\title{
CANDIDATE GENDER AND MEDIA ATTENTION IN THE 2015 UK \\ GENERAL ELECTION
}

\author{
Justin Murphy, University of Southampton \\ Beata Rek, University of Southampton
}

This is a pre-print. Please cite: Justin Murphy, Beata Rek; Candidate Gender and Media Attention in the 2015 UK General Election, Parliamentary

Affairs, https://doi.org/10.1093/pa/gsy019.

Abstract. Some scholars have argued that lower levels of media attention given to female candidates, relative to male candidates, may contribute to the under-representation of women in politics. Yet, other research suggests female candidates may receive more coverage than male candidates. To advance our understanding of this issue, we introduce and analyse a novel dataset measuring the weekly quantity of newspaper coverage given to 72 different candidates across 34 of the most marginal constituencies in the 2015 UK General Election. The data span 31 local and 6 national newspapers. Statistical analyses and two pairs of quantitatively matched, qualitative comparisons suggest that female candidates received more newspaper coverage than male candidates, even after controlling for several alternative predictors of media attention including party, incumbency, and time until election. Our findings have important implications for debates about gender equality in British politics.

Keywords: British politics, political campaign, media, local and national press, gender

Of the information technologies constituting the modern mass media, newspapers are one of the most influential (Gerber et al. 2009). In part, this is because the press transmit a high 
volume of information, which is relatively easy to acquire by readers (Druckman 2005). But even apart from the explicit information transmitted in newspapers, the political power of the press consists especially in how it distributes coverage. By giving more or less attention to certain issues or public figures, the press leads the public to perceive those issues or actors as more or less important (McCombs and Shaw 1972).

For this reason, a great deal of research has investigated the many factors that influence the quantity of press coverage given to different issues and actors. In particular, a significant current of research has sought to understand the effect of candidate gender on the quantity of press coverage given to individuals running for public office (Kahn and Goldenberg 1991; Heldman et al. 2005; Ross et al. 2013). While there has been much anecdotal research and commentary on gender bias in media coverage of politicians (Sreberny and van Zoonen 2000), there have been relatively few systematic studies focusing on candidate gender and the quantity of coverage in particular. Of the studies which have been conducted, results remain notably mixed, with some authors claiming that female politicians receive less press attention (Kahn and Goldenberg 1991; Heldman et al. 2005; Campbell and Childs 2010; Ross et al. 2013) and others finding that women receive greater coverage (Bystrom et al. 2001; Jalalzai 2006; Atkeson and Krebs 2008).

Much of the previous research on this question does not consider the role of local media and/or online editions, important 'missing links' potentially connecting media coverage of campaigns to voting behaviour (Hargreaves and Thomas 2002; Jackson 2015). Because local and national media differ in the issues they cover and how they cover those issues (Just et al. 1996; Negrine 2005), the over-reliance on national media in previous research is an important gap in the current state of knowledge on candidate gender and media coverage. The overreliance on national media is also an important shortcoming in single-country studies such as those of the United Kingdom (UK), as the prominent national newspapers in the UK have 
atypically large circulations and are predominantly centred around London. Including local newspaper reporting in the study of gender in the media is not only a desirable strategy for increasing the number of available observations, but it may increase our confidence in generalisations across the geography and circulation size of various media outlets (Meeks 2012). Finally, newspapers' digital platforms continue to be neglected by researchers, despite the readership of online editions now generally being higher than the circulation of conventional printed press (Jackson 2015). While the decline of print newspapers raises questions about the influence of the press, analysing online editions of local and national newspapers directs scholarly attention to where the press maintains its largest audiences.

We advance the previous research by introducing and analysing a novel dataset measuring national and local online press coverage of candidates in the 2015 UK General Election. The dataset covers 34 constituencies in England, selected from the 50 most marginal races involving at least one female candidate. We chose to focus our attention on the most marginal races, because they tend to be the crucial sites of party strategy and media contention during General Election campaigns (Johnston et al. 2012). Focusing on marginal seats also ensures that in all of our cases, male and female candidates both have at least decent chances of winning. If one candidate is significantly more likely to win than the others, differentials in media coverage observed across candidates could be attributed to differentials in the likelihood of winning. This would be especially problematic in the event that there exists some relationship between candidate gender and the likelihood of winning (if, for example, male/female candidates are more/less likely to run for safe seats). Additionally, we expand our analysis with quantitative identification of optimal case-comparisons selected to maximise the causal leverage of our qualitative case studies.

Surprisingly, after controlling for a wide variety of factors likely to shape the quantity of press coverage given to candidates, we find that female candidates received more press 
coverage than equivalent male counterparts in both the local and the national press. This finding emerges from statistical analyses at the local and national level, as well as by qualitative comparisons of the two most similar male-female pairings. Furthermore, we find this gender effect to be slightly more substantively significant in the local press, largely because of the low baseline quantity of coverage given to most candidates in the national press. Our findings have important implications for debates surrounding gender and political media because they help to adjudicate the mixed conclusions of previous studies. In particular, we find that, however contemporary media may disadvantage female candidates in British politics, under-reporting of female candidates appears unlikely to be the culprit.

In the next section, we begin by situating our study in previous research on candidate gender and media coverage in political campaigns. Based on our review of the literature, we identify three different possible expectations about the effect of gender on press coverage, and a fourth regarding how the local or national character of different newspapers may condition this relationship. The second section details the data and research strategy. The third section presents and discusses a series of statistical analyses, as well as two brief qualitative comparisons of optimally matched pairs of candidates. A fourth section concludes.

\section{Candidate gender and coverage quantity}

\subsection{Do female candidates receive less, more, or equal media coverage?}

The relationship between the gender of politicians and the quantity of coverage they receive has been examined in a number of studies (Kahn and Goldenberg 1991; Heldman et al. 2005; O'Neil et al. 2016). The question is particularly important because low levels of media coverage may adversely affect voters' recognition of candidates (Goldenberg and Traugott 1984; Kahn 1992) and public recognition of candidates is associated with their electoral performance (Goldenberg and Traugott 1984; Kahn 1992, Lovenduski 1997). The substantive 
political significance of this question is all the greater to the degree that contemporary voters' knowledge about candidates is gained through the media (Blight et al. 2012). Gender bias in media coverage of political campaigns is therefore a possible causal factor contributing to other gender-based inequalities in contemporary politics. For instance, this has been put forward as one of the potential reasons for the under-representation of women in the UK Parliament (Lovenduski 1997).

Considering those studies that report gender effects, there remains uncertainty about the direction of the effect. A number of scholars have found that female politicians receive less coverage than their male counterparts. For instance, Carroll and Schreiber (1997) analysed the quantity and content of press coverage during the election of the $103^{\text {rd }}$ US Congress. The election occurred during the "The Year of The Woman" and female candidates received more than usual media attention. Carroll and Schreiber (1997) attempted to verify whether this trend continued after the election. The study revealed that, while newly-elected women received more media attention than the first-time male members, soon after the election the total coverage of congresswomen rapidly declined. Kahn and Goldenberg (1991) conducted a quantitative analysis of press coverage during 26 US Senate races in years 1984-86. The findings suggest that female candidates received approximately 2.4 fewer paragraphs per day, in comparison with their male counterparts. Kahn and Goldenberg argued that this might have been due to female politicians being perceived as less viable. Similar research by Ross et al. (2013) found that during the 2010 UK General Election, about $71 \%$ of the articles released in the national press mentioned only male politicians, while only $9 \%$ mentioned exclusively female politicians, a ratio disproportionate to the total number of male and female candidates. Some studies have even suggested that British newspapers may give more attention to the average male politician's wife than the average female politician (Campbell and Childs 2010). 
Gender bias in media coverage of politicians might have structural origins in the patriarchal nature of most contemporary Western political systems. For instance, because campaigns in the UK tend to be leadership-focused (Lovenduski 1997), women may be less recognised and less reported because they are less likely to be party leaders. This is similar to claims by female candidates that their access to journalists is restricted (SrebernyMohammadi and Ross 1996). This would also be consistent with observations that male politicians and journalists tend to create environments inaccessible to female candidates (Sreberny-Mohammadi and Ross 1996). Overall, these currents of research lead to the expectation that female candidates will generally receive less media coverage than male candidates, after controlling for other predictors of media coverage.

A small number of studies have found that female candidates receive more coverage than male candidates. For instance, one analysis of newspaper articles during the 2000 US Senate elections finds a statistically significant difference favouring female candidates, with male candidates mentioned in $75 \%$ and female candidates mentioned in $95 \%$ of articles about the election (Bystrom et al. 2001). While media may have preferred to write about male candidates in the past, the authors suggest that the effect of gender on media coverage may be reversing as gender norms change (Bystrom et al. 2001). As female candidates become more common, media may become more likely to report on female candidates (Jalalzai 2006). Indeed, the study examining coverage of senatorial and gubernatorial candidates between 1992 and 2000 demonstrates that women received more press attention (measured in paragraphs) than men (Jalalzai 2006). Using one of the existing studies as a benchmark, the author indicates that coverage of female candidates improved from the 1980s (Jalalzai 2006). Some scholars also have argued that the role of gender in politics may be subject to threshold effects, in which the number of female politicians may have to meet a certain quota (Grey 
2002) before triggering an effect. In the 2015 UK General Election, females constituted 5\% more of the candidate pool than in the previous Election (Keen and Cracknell 2015).

Another reason why female candidates might be given more press attention than male candidates in the 2015 UK General Election is that this was the first General Election in which female politicians took part in televised debates. It has been argued that the absence of female participants from previous televised debates, such as the 2010 General Election debates, has strengthened the image of politics as restricted to men (Ross et al. 2013). If it is true that 'big female politicians' are needed before female politicians, in general, become visible to the public, then the 2015 televised debates including three high-visibility female politicians (Nicola Sturgeon, Natalie Bennett, and Leanne Wood) may have shifted the attitudes and behaviours of journalists toward paying greater attention to female candidates more generally. This would also be consistent with the observation that the 2015 election may have marked a retreat of masculinity in politics, with David Cameron and Ed Miliband sometimes promoting softer images in domestic settings (Wahl-Jorgensen 2015). These considerations lead to the expectation that female candidates will receive more media coverage than male candidates, after controlling for other predictors of media coverage.

Taking this field of research as a whole, studies to date have not been able to establish an unambiguous and consistent causal link between candidate gender and amounts of media coverage. First, scholars debate whether the gender of candidates at all affects the quantity of coverage they receive, with several studies having found no evidence of any gender effect. For instance, Hayes and Lawless (2015) find that the quantity of stories devoted to male and female candidates running in congressional elections are comparable. Press analysis of 30 days leading to the US House campaigns in years 2010 and 2014 also did not indicate any differences between the coverage of male and female candidates (Hayes and Lawless 2016). In particular, not only were both genders equally likely to be depicted in the press, but also no 
disparity was found in terms of references to appearance or feminine traits. To support these findings Hayes and Lawless (2016) conducted interviews with the journalists and discovered that men and women had run similar campaigns and emphasised similar issues, which were subsequently reflected by the journalists. Miller (2001) analysed press coverage of US state legislative races from 1996. Although the author indicates a gender gap in the way of presenting male and female candidates, she found no significant difference in terms of coverage quantity. Thus, the literature provides some ground for the expectation that female candidates and male candidates will not receive different quantities of media coverage, after controlling for other predictors of media coverage.

\subsection{Differences between local and national media}

Complicating debates about the relationship between gender and media coverage, it has also been found that local and national press differ with respect to the types of issues they cover and also how they cover them (Negrine 2005). Scholars have noted previously that local media may be a 'missing link' between media coverage and voting behaviour (Hargreaves and Thomas 2002). In particular, there are many overlapping associations between female gender and local politics. First, unsurprisingly, local media are more likely to report constituency matters and local candidate profiles (Vinson and Moore 2007; Franklin and Richardson 2002), whereas the national press are more likely to report on information pertaining to larger and more general political issues and policy debates (Just et al. 1996). Thus, local press may be more likely to 'personalise' the candidate, emphasising the candidate's private life and character (Franklin and Richardson 2002). As female candidates are more likely to be associated with person-centred coverage (Aday and Devitt 2001) and less likely to receive issue-related press coverage (Devitt 1999), these overlapping associations between female gender, localism, and personalisation suggest the prediction that 
local media may be more likely than national media to give female candidates more attention than male candidates. Such an expectation is supported by other empirical observations. Women, in general, are perceived to be more interested in local politics than men (Hayes and Bean 1993) and have been found to be more interested in local issues, not only as voters but also as politicians (Campbell and Lovenduski 2014). Finally, we also note that female candidates running in the 2010 UK General Elections testified to differences in the coverage they received in the local and national press (O'Neill and Savigny 2014).

Local and national journalists also enjoy different work environments. Local journalists may have more independence in establishing the content and format of articles, relative to national journalists, for whom such decisions are made at a higher level (Negrine 2005). If female candidates enjoy less access to journalists than male candidates (SrebernyMohammadi and Ross 1996), such a gender difference could be relatively exacerbated by the management styles of national media companies and relatively ameliorated by those of local newspaper companies. This current of research suggests that the difference between quantities of coverage for female candidates and male candidates may be greater (in favour of females) in local press relative to national press. Of course, it is highly unlikely that any journalists today, working for local or national media, would ever be explicitly encouraged or discouraged to cover candidates because of their gender. In this section we have only sought to consider how a number of unspoken norms could potentially function, implicitly, to produce differential gender effects in local and national press.

\section{Data and method}

To consider these various expectations empirically, we gathered data on local and national press coverage of competitive political campaigns in the 2015 UK General Election. To maximise the number of relevant observations in our sample, we began by selecting 50 of the 
most marginal constituencies in England, based on publicly available information about marginality of each constituency based on the results for the 2010 General Election (Hough 2013). We then identified those constituencies in which at least one of the two candidates (or three, in the case of a three-way marginal), from the marginal parties, was female. This produced a list of 34 constituencies with a total of 72 unique candidates to be the focus of our study. ${ }^{1}$ The major local newspaper was selected for each constituency, using publicly available information about the circulation area as well as online availability. Often there is only one local newspaper with a visible web-presence; in unclear cases, local libraries and city councils were consulted. Following Ross et al. (2013) in their study of media coverage in the 2010 General Election, we analysed six large national newspapers selected to include tabloid, mid-market, and quality national newspapers with a range of political orientations: The Guardian, The Independent, The Times, Daily Express, The Sun, and the Mirror. ${ }^{2}$ Two supported Labour, one supported the Conservatives, two supported the coalition of Conservatives and Liberal Democrats, and one supported UKIP (Deacon and Wring 2016).

The online editions of each newspaper were monitored for all 39 days of the campaign, starting from the dissolution of the Parliament on 30 March, until Election Day on 7 May. We made the decision to focus exclusively on the online editions for two reasons. First, using exclusively online editions helped to ensure that we would account for as many relevant newspapers as possible, including any that are online-only, such as The Independent. Second, this approach allows for the most consistent possible data collection through an automated computer system, as otherwise differences in the formatting and presentation of physical newspapers would increase opportunities for manual coding inconsistencies.

\footnotetext{
${ }^{1}$ A complete list of constituencies and candidates is provided in the online Supplementary Information. Among those 34 selected constituencies there were 6 retirement seats, where the ${ }^{2}$ Daily web traffic for each newspaper is as follows: The Guardian $(1,242,000)$, Mirror (477,000), Independent (397,000), Daily Express (371,000), The Sun (281,000), The Times $(89,000)$. Daily web traffic for each local newspaper is available in the Supplementary Information.
} 
The data collection was conducted with the website mirroring software (HTTrack), which downloaded the content of the articles on a daily basis. ${ }^{3}$ Overall, a total of approximately 54,000 articles were downloaded. The stories were subsequently searched with NVivo for the names of each of the 72 main candidates standing for election in the selected constituencies. This search identified 1,142 articles, comparable to a previous study of candidate press coverage based on 707 articles (Bystrom et al. 2001).

Preliminary checks of the data showed two candidates to be extreme outliers, due to exceptional nationwide prominence. Caroline Lucas and Ed Balls each received levels of press coverage more than three standard deviations above the mean. This is not surprising, as Balls was Shadow Chancellor at the time and Lucas was a former party leader and the only representative of the Green Party in the UK Parliament. Additionally, in the fourth week of the campaign, Conservative MP for Weaver Vale, Graham Evans, received an exceptionally large quantity of coverage, more than two standard deviations greater than the mean. Evans is chair of the All-Party Parliamentary Group for Running and is known for encouraging MPs to participate in the London Marathon.

An inspection of the coverage suggested that his exceptional quantity of coverage was due to his participation in the London Marathon. Because these are unique and substantial sources of media salience unrelated to the particular electoral campaigns, the processes generating media attention for each of these candidates are plainly not comparable to those obtaining for the vast majority of other candidates. We thus chose to drop all the observations for Caroline Lucas and Ed Balls and the fourth week's observation for Graham Evans. We also considered alternative ways of dealing with these outliers, such as including the observations with dummy variables for the outlier candidates. ${ }^{4}$

\footnotetext{
${ }^{3}$ HTTrack is free software under a GNU General Public License (https://www.httrack.com).

${ }^{4}$ Inclusion of dummy variables for outlier candidates does not produce results substantially different than those reported here. See Supplementary Information.
} 
Our final analytic sample consists of an unbalanced panel of 419 observations (70 candidates over 6 weeks each, with the exception of Graham Evans' fourth week). The unit of analysis is the candidate-week. Similar to previous work by Bystrom et al. (2001), our dependent variable, Coverage $_{t}$, is the count of articles mentioning a candidate in week $t$.

We use two versions of this dependent variable, one referring to the number of articles mentioning a candidate in the major local newspaper and the other referring to the number of articles mentioning a candidate in any of the national newspapers. Our key independent variable of interest, $S e x$, is a binary variable taking a value of one if the candidate is female and zero if the candidate is male. To our knowledge, all of the candidates in the election had straightforwardly identifiable sexual identities within the traditional binary. To control for other factors, unrelated to candidate's sex, that might affect the amount of coverage a candidate receives, we also gathered data on a set of potential confounders. Previous reports indicate that media attention may vary throughout the time of the campaign, with press attention picking up closer to election day (Deacon et al. 1998). To control for this, we include the variable Time, an ordinal categorical variable (i.e. categories ordered in a sequence), where each level represents each week of the campaign. To control for the possibility that the party of a candidate affects their media coverage, perhaps due to previous electoral fortunes, we include a categorical variable Party capturing the party of each candidate, with Labour as the baseline reference category. Incumbency status is an obvious factor affecting the recognisability of candidates. Thus, Incumbency is a categorical variable with three categories, one for candidates challenging an incumbent, a second for incumbents running for re-election, and a third for candidates in contests with no incumbent running. Because coverage at time $t$ is very likely affected by coverage at time $t-1$, we control for the autocorrelation of errors by including on the right-hand side of the equation Coverage Co $_{-1}-\mathrm{a}$ 
dependent variable, lagged by 1 week. The descriptive statistics for all variables are presented in Table 1.

[Table 1 Descriptive statistics]

\section{Results and discussion}

\subsection{Quantity of coverage}

In the first phase of analysis, we use a series of statistical models to estimate the relationship between candidate sex and media coverage, controlling for the confounding variables. Since the dependent variable is a count variable (a count of articles), the appropriate model should use either a Poisson or negative binomial distribution, depending on the dispersion (the amount of variance relative to the mean). We inspected the distributions of our two dependent variables. The variable for local weekly references to male candidates had a mean and standard deviation (SD) of 1.80 and 2.28 , respectively. The variable for local weekly references to female candidates had a mean and standard deviation of 2.54 and 2.18 , respectively. The variable for national weekly references to male candidates had a mean and standard deviation of 0.19 and 0.45 , respectively. Finally, the variable for local weekly references to male candidates had a mean and standard deviation of 0.42 and 0.66 , respectively. The conditional variances, i.e. corresponding to male or female candidates separately, are therefore greater than the conditional means, suggesting over-dispersion. Therefore, in our analysis, we estimate negative binomial models because they include an additional parameter to explicitly model the dispersion.

Specifically, we estimate regression equations of the form:

$$
\text { Coverage }_{t}=\alpha+\beta_{1} \text { Sex }+\beta_{2} \text { Time }+\beta_{3} \text { Party }+\beta_{4} \text { Incumbency }+\beta_{5} \text { Coverage }_{t-1}+\varepsilon
$$


where $\alpha$ is an intercept, $\beta$ is a vector of covariates, and $\varepsilon$ is the error term. We estimate two separate models, one for national press coverage and one for local press coverage. The results are displayed in Table 2, with the first column reflecting our model of local press coverage and the second reflecting our model of national press coverage. Surprisingly, the coefficients for Sex (female) are positive for both local and national press, and statistically significant at $90 \%(\mathrm{p}<0.1)$ and $95 \%(\mathrm{p}<0.05)$ confidence levels, respectively. The regression results are therefore consistent with the interpretation that female candidates receive more press coverage than male candidates, other things equal.

[Table 2 Models of local and national coverage]

The coefficients in negative binomial models are in logarithmic terms, which makes them not readily interpretable. Simulations can provide a better sense of estimated effect sizes and a better accounting of the uncertainty for each estimate. Accordingly, we conducted two simulation exercises for each model, setting Sex first to Male and then to Female, while holding the values of each covariate to their mean value or modal category. ${ }^{5}$ Figure 1 shows the distributions of predicted mentions under these different hypothetical situations. This approach provides a useful, visual illustration of the differences in media coverage for each sex, while also illustrating the uncertainty involved in probabilistic estimates from regression models. In Figure 1a, the expected number of articles mentioning the candidate for a typical male is 1.36 , with a standard deviation (SD) of 0.2 , whereas for an otherwise equivalent female it is 1.8 with a standard deviation of 0.3 . The difference is $0.44(\mathrm{SD}=0.24)$. As shown in Figure 1b, in national press, the expected number of articles mentioning the candidate for a

${ }^{5}$ All simulations and associated estimates were conducted with the $R$ package Zelig, using the default of 1000 simulations. 
typical male is $0.11(\mathrm{SD}=0.03)$, whereas for an otherwise equivalent female it is 0.2 $(\mathrm{SD}=0.06)$. The difference is $0.09(\mathrm{SD}=0.05)$.

[Figure 1 Simulations of the predicted effect of sex on media coverage.]

While the coefficient for sex is larger in the model of national press coverage compared to the model of local press coverage, these coefficients in terms of log counts cannot be directly compared because the two dependent variables have different distributions. In particular, the variance in local coverage $(\mathrm{SD}=2.43)$ is much greater than in national coverage $(\mathrm{SD}=0.58)$. If we divide the estimated effects by the standard deviations of the respective dependent variables, the standardised effect of candidate sex is slightly larger on local press coverage. Specifically, a hypothetical change from male to female sex of an otherwise equivalent candidate will be associated with an increase of local press mentions equal to 0.18 standard deviations, whereas the expected increase in national press mentions would be equivalent to 0.15 standard deviations. While this is weakly consistent with the expectation that a female premium in coverage quantity would be greater in local press relative to national press, a comparison of the effect sizes as visualised in Figure 1 suggests that this difference is modest. As Figure 1a and Figure $1 \mathrm{~b}$ both reveal, on average, female candidates received more press coverage in local and national press, in the bivariate and multivariate senses.

\subsection{Quality of Coverage}

Although our focus is on quantities of media coverage, we briefly consider the question of coverage qualities. Media coverage may be qualitatively biased against female candidates (Aday and Devitt 2001; Heldman et al. 2005). Women's quantitative visibility in campaign 
coverage will not necessarily be associated with equally favourable coverage quality (Bystrom et al. 2001). In particular, research suggests female candidates are more likely to be discussed in relation to personal issues, such as appearance, gender, marital status, and children (Bystrom et al. 2001). This may be disadvantageous as, for instance, Murray (2010) reported that references to appearance may trivialise female candidates and thus make it harder to get their message across. In an analysis of newspaper articles and interviews with female politicians, O’Neill and Savigny (2014) concluded that emphasising gender of female politicians may mark their 'otherness' in the world of politics and reinforce the perception of the 'maleness' of political jobs. A language analysis of British press by Insenga (2014), showed that focus on private lives of female politicians (e.g. marital status, children, etc.) may suggest that women have 'liabilities' in the form of domestic duties, which ultimately may undermine their suitability for the office. While the effect of candidate gender on coverage quantity is the focus of this study, we briefly investigate the question of coverage quality.

We coded each article in our study for any mention of appearance, gender, marital status, and children. Of 1142 coded articles, 35 mentioned at least one of the analysed issues (20 in national and 15 in local press). We then created a new media coverage variable, similar to our original coverage variable, equal to the number of articles in which any of these personal issues were mentioned about a candidate. This produced a panel data set similar to the original dataset analysed above. As above, the dependent variable (number of personalistic mentions), is over-dispersed. Therefore we estimated negative binomial models for local and national press, using the same approach outlined above, including a lagged dependent variable on the right-hand side of the regression equation. We find that, in national press, female candidates are more likely to have their personal issues mentioned relative to men, at a $90 \%$ confidence level $(\beta=2.49, p<.1)$. By contrast, the local press is neither more nor less 
likely to cover female candidates in a personalistic lens. Full numerical results are presented in the Supplementary Information.

\subsection{Robustness checks}

To check the robustness of our main results on coverage quantity, we conducted several auxiliary analyses. One common problem with time series data is autocorrelation, a phenomenon whereby past events are correlated with future events, which can lead to spurious inferences. The typical guard against autocorrelation is to include the lag of the dependent variable on the right-hand side of the equation, as we did above, but inclusion of a lagged dependent variable is not always enough to fully remove autocorrelation. To consider this, we estimated a simplified OLS version of our models on the logarithm of press mentions (a common technique for making count data amenable to OLS), and conducted the BreuschGodfrey test for panel models, a common tool for assessing the serial correlation of errors in panel data. The test suggested the presence of autocorrelation even after inclusion of a lagged dependent variable. However, given that our time series are short and most of our predictors are time-invariant, including additional lags of the dependent variable is not feasible. To check for the possibility that our results are spurious artefacts of autocorrelation, we estimated separate cross-sectional models for each week to remove the time-serial dimension altogether. A significant drawback of this approach is a loss of information, as the number of observations used to estimate each week's model is significantly less than in our first, main models.

Table 3 shows the results of our models for local and national press coverage, for each week separately. Column 7 (Total), in each table, shows the results using the total number of mentions throughout the six-week period as the dependent variable, equal to all of a candidate's press mentions each week cumulated as a single value. As Table 3 shows, the 
coefficient for sex in each week is signed as expected in five of the seven models and statistically significant in weeks two and four for local press. Similarly, for national press, the coefficient for sex in each week is signed as expected in all of the models and statistically significant in weeks one, five, and six. The model for cumulative national mentions also shows a statistically significant and positively signed coefficient for sex.

[Table 3 Models of local and national coverage by week]

\subsection{Matching-Based Case Comparisons}

Our statistical models have controlled for various factors other than candidate sex, but if male and female candidates are systematically different with respect to these control variables, then our statistical results would be biased (Rosenbaum and Rubin 1983). To explore this possibility, we use a quantitative matching algorithm to identify paired cases of male and female candidates who are, in our sample, as similar as possible on key covariates (Nielsen 2016). ${ }^{6}$ This procedure also has the benefit of preventing the analyst from cherry-picking cases consistent with the analyst's expectations. After identifying the pairs of cases that are maximally balanced on all the observed control variables other than sex, we examine the levels of media coverage for each candidate within each matched pair. If we find higher levels of media coverage for the female candidate, then it would increase confidence in our statistical finding.

To make this within-case analysis as effective as possible, in addition to party affiliation and incumbency status, we also balance on candidates' final vote share. Male or female candidates may receive more or less coverage because they are more or less likely to have public support. One example of this possibility is if male or female candidates are more or

\footnotetext{
${ }^{6}$ The analysis in this section was conducted using the $R$ package caseMatch. We used Mahalanobis distance as the distance measure to minimise between cases.
} 
less likely to run for safe seats. In each case, we would incorrectly infer that candidate sex shapes quantities of press coverage when in fact press coverage is a function of a candidate's likelihood of winning. By balancing on election results as well as incumbency status and party affiliation we ensure that we are comparing male and female candidates with similar chances of election. One drawback of this is the possibility that media coverage affects election results, in which case balancing on election results would not identify cases of similar underlying popularity, but rather cases with different levels of pre-media popularity. While this is a possibility, we think that any effect media coverage might have on candidate vote share would likely be smaller than the drastic differences in vote share within our sample (reflecting relatively large underlying differences in public support for competing candidates across constituencies). Therefore, even if media coverage affects vote share, balancing on vote share as a proxy for ex-ante public support should nonetheless provide more closely matched and less biased comparisons.

The matching algorithm identified Anna Soubry and Mark Spencer as a first pair, and Nicola Blackwood and David Morris as a second pair. The candidates within each pair are nearly identical with respect to the observed covariates. Incidentally, each candidate in each pair also started their careers in the same year, effectively ruling out candidate experience as a possible confounder we did not consider in the quantitative analyses. The first pair of cases identified by the matching procedure included Anna Soubry (female), the incumbent Conservative MP in Broxtowe who retained her seat with $45.2 \%$ of the vote, and Mark Spencer (male), the incumbent Conservative MP in Sherwood who retained his seat with $45.0 \%$ of the vote. Soubry and Spencer both started their parliamentary careers by winning in Broxtowe and Sherwood in the 2010 General Election. During her first term in Parliament, Soubry served as a junior minister at the Ministry of Defence and then at the Department of Health. Spencer acted as a member of the Environment, Food and Rural Affairs Committee, 
the Backbench Business Committee and the Environmental Audit Committee. It is also worthy of note that despite running from different constituencies, the local press coverage of both Soubry and Spencer was collected from the same newspaper (Nottingham Post).

The pair of cases identified as the second most similar included Nicola Blackwood (female), the incumbent Conservative MP in Oxford West and Abingdon who retained her seat with $45.5 \%$ of the vote, and David Morris (male) the incumbent Conservative MP in Morecambe and Lunesdale who retained his seat with $45.7 \%$ of the vote. Each candidate started their career in 2010 by winning each of these constituencies for their first time. They both worked as parliamentary Select Committee members. Furthermore, we found no evidence that any particularly unique, remarkable or sensational issue appeared in the coverage of any of the candidates during their 2015 campaigns. In an informal review, each candidate's coverage appeared typical, consisting largely of reports about campaign activities and "horse race" coverage about the likelihood each candidate would retain their seat. In summary, we are aware of no particularly striking differences between the candidates of each matched pair, other than sex. Figure 2 plots the cumulative quantities of media coverage received by each candidate identified by our matching procedure.

[Figure 2 Comparison of press coverage quantity for paired cases of male and female candidates]

Each line in Figure 2 represents the number of articles received each week plus the number of all articles received prior to that week. In the left facet, we can see that Soubry received slightly more coverage than Spencer in the first two weeks, before maintaining a clear advantage in her total quantities of local and national coverage over the next four weeks. In particular, during week three Soubry received a large spike in coverage relative to Spencer, 
followed by similar levels of coverage thereafter. For each type of coverage, the ultimate difference is substantial, with Soubry receiving six more local articles and five more national articles than Spencer. Considering Blackwood and Morris, Blackwood received more local and national coverage than Morris in the first week, and this advantage was maintained with only a few slight changes in the differential over the course of the campaigns. Ultimately Blackwood received six more local articles, and two more national articles, than Morris.

\section{Conclusion}

This study has found that, in the 2015 UK General Election, female candidates did not suffer from receiving less media coverage than their male counterparts, before or after controlling for other factors such as party membership and incumbency status. Indeed, our statistical results suggest that, on average, a female sex earned slightly more media coverage than a male sex (about $44 \%$ of an additional mention in the local press, and $9 \%$ of an additional mention in the national press). After identifying the most exactly matched pairs of male and female candidates, we found that female Anna Soubry of Broxtowe received more local and national coverage than Mark Spencer of Sherwood, despite that they were both incumbent Conservative MPs who won nearly identical shares of the vote. We found the same pattern in our comparison of female Nicola Blackwood and male David Morris, two candidates also highly similar on every observed variable other than sex.

Our findings have important implications for current research on the politics of gender and media. First, it remains widely believed that female candidates in the UK receive less media coverage than male candidates (Campbell and Childs 2010; Carroll and Schreiber 1997), leading to the under-representation of women in parliament (Kahn and Goldenberg 1991). This article shows that, at least in the 2015 UK General Election, this conventional wisdom is incorrect. Second, our findings show that local newspapers may be an under- 
studied site for the negotiation of gender in contemporary British politics. As we report, the typical candidate for MP, male or female, is more likely to receive coverage from their local newspaper than any one of the national news outlets. While both national and local newspapers write more articles about female candidates than male candidates, because the local press are more likely to focus on local candidates than national press, the gender differential is arguably more substantively significant in the local press. Our findings are therefore consistent with other research finding that local newspapers deserve greater attention as a neglected channel through which media coverage of campaigns shapes public opinion and political behaviour (Hargreaves and Thomas 2002; Blight et al. 2012).

This article also raises some questions and avenues for future research. First, a clear limitation of our study is that we do not consider the role of broadcast or social media. Our study cannot speak to whether television, radio, or decentralised online attention to candidates is shaped by their gender, an important question that must be left to future research. Another question is whether the relationship between candidate gender and media attention has been misunderstood in previous research. For instance, one possibility is that previous research found female candidates to receive less coverage because of differences in research design and/or sampling. If researchers have been disproportionately interested in cases of observed anti-female sexism (for good normative reasons), selection bias may contribute to the belief that female candidates receive less coverage than male candidates.

Another possibility is that the relationship between candidate gender and media coverage has changed over time. It is conceivable that in the past, even the very recent past, female candidates generally received less coverage than male candidates but, due to changing gender norms, female candidates are becoming more newsworthy than male candidates. Or is the relationship simply more conditional and context-dependent than previously thought, possibly subject to random, idiosyncratic factors that produce different findings in different 
studies? It is worthy of note that focusing on a single election limits generalisations of the outcomes of this study, as it is possible that the 2015 UK General Election was in some way characterised by atypical conditions pushing female politicians to the fore. For example, has the unusually high count of female party leaders, or their presence in the televised debates, contributed to the results? All of these questions should be investigated by future research.

While it is widely believed that the media cover female and male politicians differently with respect to tone and content (O'Neil et al. 2016; Ross et al. 2013; Aday and Devitt 2001), our findings here suggest that gender bias in coverage content is less prevalent in local media than in national media. But an important limitation of our study is that we do not consider many aspects of coverage content or quality, as our focus here has been on coverage quantity. Thus, future research may want to consider more systematically the degree to which gender bias in media coverage is different in local and national media. 


\section{References}

Aday, S. and Devitt, J. (2001) 'Style over substance: Newspaper coverage of Elizabeth Dole's presidential bid’, The International Journal of Press/Politics, 6(2), 52-73.

Atkeson, L. R. and Krebs, T. B. (2008) 'Press coverage of mayoral candidates: The role of gender in news reporting and campaign issue speech', Political Research Quarterly, 61(2), 239-252.

Blight, M. C., Schlehofer, M. M., Casad, B. J. and Gaffney, A. M. (2012) 'Competent enough, but would you vote for her? Gender stereotypes and media influences on perceptions of women politicians', Journal of Applied Social Psychology, 42(3), 560-597.

Bystrom, D. G., Robertson, T. A. and Banwart, M. C. (2001) 'Framing the fight, an analysis of media coverage of female and male candidates in primary races for governor and U.S. Senate in 2000', American Behavioral Scientist, 44(12), 1999-2013.

Campbell, R. and Childs, S. (2010) 'Wags', 'wives' and 'mothers'... But what about women politicians?', Parliamentary Affairs, 63(4), 760-777.

Campbell, R. and Lovenduski, J. (2014) 'What should MPs do? Public and parliamentarians' views compared', Parliamentary Affairs, 68(4), 1-19.

Carroll, S. and Schreiber, R. (1997) 'Media coverage of women in the $103^{\text {rd }}$ congress' In: Norris, P. (ed.), Women, Media, and Politics, New York, Oxford University Press.

Deacon, D., Golding, P. and Billig, M. (1998) 'Between fear and loathing: National press coverage of the 1997 British general election', British Elections Parties Review 8(1), 135 149 .

Deacon, D. and Wring, D. (2016) 'Still Life in the Old Attack Dogs: The Press' In: Cowley, P. and Kavanagh, D. (eds.), 'The British General Election of 2015', Basingstoke, Palgrave Macmillan.

Devitt, J. (1999) 'Framing gender on the campaign trail: Women's executive leadership and the press', Washington, DC, Women's Leadership Fund.

Druckman, J. N. (2005) 'Media matter: How newspapers and television news cover campaigns and influence voters', Political Communication, 22(4), 463-481.

Franklin, B. and Richardson, J. (2002) 'A journalist's duty? Continuity and change in local newspaper reporting of recent general elections', Journalism Studies, 3(1), 35-52.

Gerber, A. S., Dean, K. and Daniel, B. (2009) 'Does the media matter? A field experiment measuring the effect of newspapers on voting behavior and political opinions', American Economic Journal: Applied Economics, 1(2), 35-52.

Goldenberg, E. N. and Traugott, M. W. (1984) 'Campaigning for Congress', Washington, DC, Congressional Quarterly Press. 
Grey, S. (2002) 'Does size matter? Critical mass and New Zealand's women MPs', Parliamentary Affairs, 55(1), 19-29.

Hargreaves, I. and Thomas, J. (2002) 'New News, Old News', London, Broadcasting Standards Commission/Independent Television Commission.

Hayes, B. C. and Bean, C. S. (1993) 'Gender and local political interest some international comparisons', Political Studies, 41(4), 672-682.

Hayes, D. and Lawless, J. L. (2015) 'A non-gendered lens? Media, voters, and female candidates in contemporary congressional elections', Perspectives on Politics, 12(1), 95118 .

Hayes, D. and Lawless, J. L. (2016) 'Sex is no story' In: Hayes, D. and Lawless, J. L. (eds.), 'Women on the run - gender, media, and political campaigns in a polarised era', Cambridge, Cambridge University Press.

Heldman, C., Carroll, S. J. and Olson, S. (2005) 'She brought only a skirt: Print media coverage of Elizabeth Dole's bid for the Republican presidential nomination', Political Communication, 22(3), 315-335.

Hough, D. (2013) 'Marginal Seats', House of Commons Library, London. Accessed at: http://researchbriefings.parliament.uk/ResearchBriefing/Summary/SN06549 on 6 June 2017.

Insenga, M. (2014) 'An analysis of the representations of female members of the United Kingdom Parliament in the British Press', European Scientific Journal, 2, 182-191.

Jalalzai, F. (2006) 'Women candidates and the media: 1992-2000 elections', Politics \& Policy, 34(3), 606-633.

Johnston, R., Cutts, D., Pattie, C. and Fisher, J. (2012) 'We've got them on the list: Contacting, canvassing and voting in a British general election campaign', Electoral Studies, 31(2), 317-329.

Just, M. R., Crigler, A. N., Alger, D. E., Cook, T. E., Kern, M. and West, D. M. (1996) 'Crosstalk: Citizens, candidates, and the media in a presidential campaign', Chicago, University of

Chicago Press.

Kahn, K. F. (1992) 'Does being male help? An investigation of the effects of candidate gender and campaign coverage on evaluations of U.S. Senate candidates', The Journal of Politics, 54(2), 497-517.

Kahn, K. F. (1994) 'The Distorted Mirror: Press Coverage of Women Candidates for Statewide Office', The Journal of Politics, 56(1), 154-173.

Kahn, K. F. and Goldenberg, E. N. (1991) 'Women candidates in the news: An examination of gender differences in U.S. Senate campaign coverage', Public Opinion Quarterly, 55(2), 180-199. 
Keen, R. and Cracknell, R. (2015) 'Women in Parliament and Government', London, House of Commons Library.

Lovenduski, J. (1997) 'Gender politics: A breakthrough for women?', Parliamentary Affairs, 50(4), 708-719.

McCombs, M. E. and Shaw, D. L. (1972) 'The agenda-setting function of mass media', Public Opinion Quarterly, 36(2), 176-187.

Meeks, L. (2012) 'Is she "man enough"? Women candidates, executive political offices, and news coverage', Journal of Communication, 62(1), 175-193.

Miller, G. (2001) 'Newspaper coverage and gender', Women \& Politics, 22(3), 83-100.

Murray, R. (2010) 'Cracking the highest glass ceiling: A global comparison of women's campaigns for executive office', California, Praeger.

Negrine, R. (2005) 'The role of the UK local press in the local constituency campaign', Journalism Studies, 6(1), 103-115.

Nielsen, R. A. (2016) 'Case selection via matching', Sociological Methods \& Research, 45(3), 569-597.

O'Neil, D., Savigny, H. and Cann, V. (2016) 'Women politicians in the UK press: not seen and not heard?', Feminist Media Studies, 16(2), 293-307.

O'Neill, D. and Savigny, H. (2014) 'Female politicians in the British press: The exception to the 'masculine' norm?', Journalism Education, 3(1), 6-27.

Rosenbaum, P. R. and Rubin, D. B. (1983) 'The central role of the propensity score in observational studies for causal effects', Biometrika, 70(1), 41-55.

Ross, K., Evans, E., Harrison, L., Shears, M. and Wadia, K. (2013) 'The gender of news and news of gender: A study of sex, politics, and press coverage of the 2010 British general election', The International Journal of Press/Politics, 18(3), 3-20.

Sreberny, A. and van Zoonen, L. L. (2000) 'Gender, Politics and Communication', New York, Hampton Press.

Sreberny-Mohammadi, A. and Ross, K. (1996) 'Women MPs and the media: Representing the body politic', Parliamentary Affairs, 49(1), 103-115.

Vinson, D. C. and Moore, W. V. (2007) 'The campaign disconnect: Media coverage of the 2000 South Carolina presidential primary’, Political Communication, 24(4), 393-413.

Wahl-Jorgensen, K. (2015) 'The kitchen as the new campaign battleground: Changing notions of masculinity' In: Jackson D. and Thornsen E. (eds.), 'UK election analysis 2015: Media, voters and the campaign', Poole, The Centre for Study of Journalism, Culture and Community, Bournemouth University. 